\title{
Resistência ou Conflito? 0 legado folclorista nas atuais representações do jogo da capoeira
}

\section{Simone Pondé Vassallo A PRODUÇÃO DOS FOLCLORISTAS ${ }^{1}$}

UERJ

A partir da década de 1930, a emergência do paradigma culturalista, no Brasil, contribui para a elaboração de um novo olhar sobre a cultura popular. Autores como Édison Carneiro, Arthur Ramos, Renato Almeida, Câmara Cascudo e Gilberto Freyre, entre outros, lançam-se num projeto de busca de nossas expressões culturais mais autênticas, tidas como aquelas que melhor expressariam a singularidade da identidade brasileira.

Esta busca de autenticidade está relacionada ao projeto de construção da identidade brasileira, característico da política fortemente nacionalista do governo Vargas. Neste período, bem como nos outros que o sucedem, só a cultura verdadeiramente "autêntica" pode exprimir a "essência" da nacionalidade. Assim, a identidade e a cultura brasileira transformam-se rapidamente em "questões de estado" (Schwarcz 1995). Neste contexto, a mestiçagem, vista como solução unificadora da nação, é apontada como a nossa genuinidade, a nossa singularidade cultural. Cria-se então um mito de origem, ou uma "fábula das três raças" (Da Matta 1993), cristalizada na obra de Gilberto Freyre, segundo a qual três elementos (o negro africano, o português branco e o nativo indígena) teriam se fundido harmoniosamente no Brasil. A partir de uma perspectiva em que as fronteiras entre raça e cultura não são tão claramente delimitadas como se poderia supor (Martínez-Echazábal 1998), o folclore - e mais especificamente as festas e os jogos - passa a ser considerado o lugar por excelência da cordialidade que perpassa as relações entre os diferentes grupos sociais e étnicos, celebrando a condição sincrética da cultura e da raça brasileiras (Vilhena 1997).

Paralelamente, os estudos sobre o folclore que marcam o período situado entre os anos 1930 e 1960 são orientados por uma política de resgate das manifestações culturais populares. Acreditam que estas estariam em via de desaparecimento num 
sistematizar e preservar todo o material encontrado. É neste sentido que Édison Carneiro declara que "o processo de decomposição da capoeira se acelera [...], o progresso lhe dará, cedo ou tarde, o tiro de misericórdia" (Carneiro 1937:159-160). Assim, estes estudos percebem o folclore a partir da sua extrema alteridade em relação à cultura dominante, que se crê moderna e civilizada. A cultura popular é vista como um nicho de arcaísmo num mundo moderno e os negros se tornam os primitivos internos, vistos como africanos, e não como brasileiros. Situam-se além da dimensão sociológica (Dantas 1988).

Diante das ameaças de dissolução e de sincretismo, vários autores se dedicam à busca desenfreada das manifestações populares mais "puras", que teriam sido preservadas apesar da modernização do país. Tentam encontrar a África no Brasil e, portanto, as expressões culturais que consideram ser mais genuinamente africanas. É neste sentido que Câmara Cascudo tenta retraçar a rota da capoeira, desde sua suposta origem africana até a sua difusão pelo Brasil (Cascudo 1967). Segundo ele, a capoeira é uma arte africana e, mais especificamente, da região da atual Angola, onde encontra-se o seu ancestral: o n'golo (Cascudo 1967). Para os pesquisadores em questão, a análise das expressões culturais deve ser dada pela sua origem, e não pelo significado que possuem para aqueles que as veiculam. Assim, haveria uma continuidade das tradições africanas que teriam sido transplantadas para o Brasil e que teriam sido conservadas graças à memória coletiva negra. Trata-se do que Roger Bastide chamou de "folclore africano" na diáspora americana (Bastide 1996 [1968]). Em contrapartida, as etnias que mesclassem seus costumes a outras tradições culturais, descaracterizando sua pureza inicial, seriam aculturadas.

Nestas análises, os povos bantos tendem a ser vistos como dóceis, festeiros e dados ao sincretismo, ao passo que os nagôs seriam os mais organizados em termos culturais e, portanto, os que teriam resistido melhor à assimilação branca (tal é o caso para Bastide 1971 [1960], Freyre 1988 [1944], Viana Filho 1988 [1944]). A recorrência das representações acerca do espírito rebelde e resistente dos nagôs é tamanha que chega a constituir uma espécie de dogma nos estudos afro-brasileiros (Capone 2000). Assim, estes são pensados a partir de uma suposta atitude de rebelião e isolamento (Viana Filho 1988), ou ainda de uma maior consciência dos valores de sua cultura, o que os torna mais insubmissos e garante a pureza de suas expressões culturais, sobretudo de sua religião (Freyre 1988). Os bantos, ao contrário, são louvados por seu caráter lúdico, festeiro e dócil (Carneiro 1937), e também tagarela, superficial, brincalhão e até dissimulado (Amaral s.d.). Por isso, deteriam o monopólio do folclore negro, mas seriam mais propensos à aculturação. No entanto, alguns autores contemporâneos, como Dantas (1988), Boyer (1993) e Capone (1999), mostram que o que tende a ser interpretado como uma maior capacidade de resistência também pode ser visto como um movimento de adaptação à sociedade dominante.

Ainda de acordo com a perspectiva desses folcloristas e de seus contemporâneos, as atividades culturais são dotadas de uma "essência" que não deve ser alterada, pois esta se torna a "prova" da capacidade de resistência e não conformismo do povo que a veicula. Bastide chega a falar num processo de "mineralização cultural", que consistiria na imobilização de determinadas expressões culturais africanas no continente americano. A ameaça constante do sincretismo teria levado a este "mecanismo de defesa" (Bastide 1996).

A ênfase da perspectiva culturalista recai na noção de cultura. O que importa, nesse caso, é avaliar o grau de contaminação ou de pureza do legado cultural africano no Brasil. A resistência de que se fala é sobretudo 
cultural, ou seja, vinculada a uma suposta capacidade de um grupo, étnico ou não, em não se deixar contaminar pelas influências culturais de outros grupos. As expressões culturais que melhor preservam as suas características supostamente originais e genuinamente africanas são as consideradas mais puras e autênticas. Neste sentido, em alguns trabalhos, os bantos também são percebidos a partir de uma ótica da resistência. No caso da capoeira, esta característica melhor se expressaria numa modalidade específica, a Capoeira Angola, considerada mais pura que sua variação chamada de Regional ${ }^{2}$. Apesar da suposta propensão banto ao sincretismo, tal tendência não teria se expressado na esfera do jogo da capoeira em sua versão chamada de Angola.

Em alguns momentos, a resistência também pode ser política mas, neste caso, ela diz respeito a um momento passado e remoto da história, e não ao presente. Tal é o caso da versão rural da origem da capoeira, consolidada por autores como Édison Carneiro, Renato Almeida e Câmara Cascudo. Para eles, o combate afro-brasileiro teria sido praticado inicialmente nas senzalas das grandes plantações, durante o período da escravidão. Graças a esta atividade, os negros cativos teriam conseguido lutar contra seus senhores e conquistar a liberdade. Assim, segundo Édison Carneiro, a capoeira "era antes uma forma de luta, muito valiosa na defesa da liberdade de fato ou de direito do negro liberto" (Carneiro 1975: 3). As pesquisas etimológicas vão no mesmo sentido. Baseados em trabalhos de Macedo Soares, entre outros, acreditam que o termo capoeira consistiria inicialmente no mato que abriga os lutadores afro-brasileiros fugidos das plantações. A partir de um processo metonímico, a violenta luta destes escravos fugitivos também teria se chamado capoeira (Almeida 1961 e Carneiro 1975). Mas essa luta só diz respeito a um momento passado. No presente, a capoeira seria a pura expressão da cordialidade entre os povos. É nesse sentido que Carneiro parece afirmar que

“tanto a repressão policial quanto as novas condições sociais fizeram com que, há cerca de cinqüenta anos, se tornasse finalmente um jogo, uma vadiação entre amigos. Com esse caráter inocente a capoeira permanece na Bahia (...). Trata-se de um combate singular em que os 'moleques de sinhá' apenas demonstram a sua capacidade de ataque e defesa sem, contudo, atingir efetivamente os oponentes" (Carneiro 1975: 3).

O mesmo autor declara que a capoeira "é, mais do que uma arma de luta individual, uma brincadeira coletiva. O capoeira baiano se diverte entre amigos" (Carneiro 1950: 68). Ainda para ele, “os capoeiras da Bahia denominam o seu jogo de vadiação - e não passa disto a capoeira, tal como se realiza nas festas populares da cidade. Os jogadores se divertem fingindo lutar" (Carneiro 1975: 9). No entanto, este aspecto lúdico seria uma especificidade baiana que não se encontraria na capoeira das outras regiões do país. De acordo com Luís da Câmara Cascudo,

“Na Bahia, o capoeira luta com adversários, mas possui um aspecto particular e curioso, exercitando-se amigavelmente, ao som de cantigas e instrumentos de percussão, berimbau, ganzá, pandeiro, marcando o aceleramento do jogo o ritmo dessa colaboração musical" (Cascudo 1993 [1954]: 193).

Roger Bastide também chama atenção para a particularidade baiana, que descreve como um "balé de luzes, reviravoltas e outros passos acrobáticos", por oposição à "luta corporal [...] utilizada outrora pelos malandros do Rio" (Bastide 1996: 181). Assim, no momento presente, a capoeira é, indiscutivelmente, uma atividade amistosa, uma dança, uma brincadeira entre amigos. 
De acordo com Édison Carneiro, a repressão policial, bem como as novas condições sociais, teriam sido responsáveis pela preservação da luta baiana como uma tranqüila vadiação. Para este autor, a capoeira baiana, considerada mais lúdica, seria mais antiga que as suas variantes mais violentas praticadas em outras localidades, o que atestaria a sua superioridade em relação às demais. Neste sentido, declara que

“O caráter de afirmação pessoal, de arma de sobrevivência, que a capoeira assumiu no Rio de Janeiro e mais tarde no Recife, não chegou a se pronunciar na Bahia. Parece, mesmo, que a forma de capoeira ali existente, que não passa de uma diversão, de uma competição amistosa, está mais próxima das suas origens. A lentidão do ritmo do progresso na província, sem grandes comoções sociais, não modificou a situação relativa das classes, nem deu nova fisionomia à vida urbana" (Carneiro 1950: 67).

A modalidade lúdica não é apenas baiana, mas também a mais pura, a mais próxima de suas origens e a menos influenciada pela modernidade, pelo progresso e pelo fenômeno de urbanização e de formação de uma sociedade de classes e de massa, que caracterizam o Sudeste. A violência fez parte de um momento passado de sua história, de uma deturpação passageira que caracterizou a capoeira no Rio de Janeiro e em Recife. Omitem-se os constantes conflitos com a polícia de que os capoeiristas, inclusive baianos, foram alvo nas primeiras décadas do século XX.

Consolida-se assim a versão histórica da origem rural desta atividade que, nas últimas décadas, foi questionada por alguns historiadores. Para estes, é mais provável que esta luta seja uma atividade eminentemente urbana, tendo se desenvolvido em cidades como o Rio de Janeiro, entre outras (Holloway 1989, Pires 1996, Soares 1994 e 2001). Progressivamente, a idéia de que a capoeira mais autêntica é a mais lúdica e menos violenta toma conta do imaginário de capoeiristas e intelectuais (Vassallo). E esta é representada pelo Jogo de Angola, em detrimento da Regional. O elemento lúdico, também chamado de vadiação ou brincadeira, passa a encarnar a verdadeira essência da capoeira. A violência é atrelada à capoeira carioca do século XIX, ou seja, ao passado, ao passo que a brincadeira encarna o presente da capoeira baiana, na pena dos folcloristas em questão. Ou melhor, a brincadeira representa a essência da capoeira e, nesse sentido, é atemporal.

Os trabalhos dos autores mencionados acima são perpassados por uma perspectiva bastante idealizada das relações raciais na sociedade brasileira, onde o preconceito racial é minimizado. Nestas abordagens, a cultura popular passa a ser vista como o espaço por excelência da convivência pacífica entre raças e classes, onde a nossa mestiçagem teria melhor se expressado. Diante da necessidade de se exorcizar o nazismo e outras práticas segregacionistas, o Brasil surge como um modelo de relações harmoniosas a ser seguido.

A perspectiva culturalista adotada pelos folcloristas mencionados acima percebe a cultura a partir do seu conjunto de itens, ou traços, que podem ser medidos, observados, analisados isoladamente, independentemente do contexto ao seu redor. Percebemos que, de acordo com este ponto de vista, "essência", "pureza" e "resistência" são elementos que caminham juntos, e que se opõem a "descaracterização", "impureza" e "aculturação" ou "sincretismo". Cria-se, assim, uma percepção dicotômica das expressões culturais, cindidas entre cultura erudita e cultura popular, mundo moderno e mundo arcaico ou tradicional, cada qual dessas esferas vista como compondo um bloco coeso e homogêneo. 
A partir dos anos 1970 e 1980, o recrudescimento dos movimentos de reivindicação da negritude contribui para a reelaboração das polaridades mencionadas acima. A cultura afro-brasileira adquire uma nova conotação política, cuja tônica reside na denúncia da dominação racial. Ela se transforma em "cultura negra", símbolo de resistência à dominação. A luta política se desloca para o presente e exorta os negros à reação. Trata-se, agora, de uma imagem veiculada pelos próprios negros a respeito de si. No entanto, só as expressões culturais consideradas genuinamente africanas, ou puras, podem atuar como ícones de insubordinação. As que possuem elementos supostamente brancos e ocidentais são acusadas de reproduzir um modelo de sincretismo e assimilação. A mestiçagem, louvada pelos folcloristas das décadas anteriores, é denunciada como uma atitude de conformismo e acomodação dos negros aos valores e práticas da sociedade dominante. Gilberto Freyre e outros são acusados de terem caricaturado o negro brasileiro, transformando-o num elemento pitoresco e exótico na sociedade brasileira (Vilhena 1997). A idéia de harmonia das relações raciais no Brasil também é duramente criticada e várias pesquisas que desvendam o preconceito racial na nossa sociedade emergem no panorama intelectual. No entanto, os parâmetros de pureza e impureza preconizados pelos folcloristas do período anterior são retomados. As tradições africanas consideradas mais "autênticas" por estes são aquelas que devem ser "recuperadas" pelo movimento negro, pois simbolizam a insubmissão ao modo de vida dominante dos que tentam preservá-las. Os ícones do tradicionalismo continuam sendo o candomblé (em detrimento da macumba do Sudeste) e a Capoeira Angola (por oposição à Regional). Apesar da crítica aos defensores da democracia racial, as definições do que é puro ou espúrio permanecem inalteradas. Uma nova perspectiva ideológica baliza este campo de atividades, efetuando uma releitura da obra dos folcloristas sem, no entanto, descartá-la.

Neste novo contexto, a capoeira, sobretudo em sua versão Angola, emerge como um dos grandes ícones da resistência negra, e a sua representação como "luta pela liberdade", sugerida por Édison Carneiro, adquire novos contornos. Para capoeiristas e para intelectuais, esta atividade passa a ser definida como a luta de libertação do povo oprimido contra o opressor. Tais representações se perpetuam nos dias de hoje: um dos mestres mais conhecidos da atualidade, em entrevista a uma revista francesa, declarou que "a capoeira é a luta do fraco contra o forte, do oprimido contra o opressor, é a luta da liberdade". Em muitas escolas de capoeira, constatamos a veiculação do mito de origem sugerido pelos folcloristas, em que a capoeira teria sido criada pelos negros na senzala como uma forma de lutar contra os senhores opressores e de adquirir a liberdade. O próprio senso comum veicula estas representações, ao definir a capoeira como uma luta que os negros das senzalas disfarçavam sob a forma de dança. Assim, fingiam dançar quando estavam, na realidade, exercitando-se na luta que os conduziria à fuga. Zumbi emerge como um personagem mítico que encarna a insubmissão ao sistema escravocrata e a aquisição da liberdade. Tais relatos compõem a memória da luta afro-brasileira veiculada pelos mestres e transmitida às novas gerações de capoeiristas, contribuindo substancialmente para a elaboração das novas identidades coletivas. 
A partir dos anos 1980, criam-se escolas de capoeira que afirmam praticar exclusivamente a Capoeira de Angola, por ser considerada mais pura e tradicional. Trata-se dos chamados angoleiros. Estes acusam permanentemente a Capoeira Regional de descaracterização e assimilação, ao passo que o Jogo de Angola remete à matriz africana que deve ser retomada. Neste caso, só esta última modalidade seria digna de encarnar a resistência, enquanto a Regional é tida como sinônimo de assimilação. A cultura é vista sob um prisma essencializado que a torna uma mera reprodução do que já foi no passado, não podendo ser alterada.

Júlio César Tavares, um dos primeiros acadêmicos do período em questão a realizar um trabalho sobre capoeira, afirma explicitamente esta oposição (Tavares 1984). Outros autores, que não compactuam necessariamente com esta oposição radical, acabam reproduzindo-a em algumas passagens, como Luiz Renato Vieira (1990) e Letícia Vídor de Souza Reis (1993). Uma outra imagem bastante veiculada e que se articula à que foi mencionada anteriormente diz respeito à suposta capacidade da cultura negra/popular de atuar nos "interstícios do poder". A malandragem, a finta, a malícia, surgem como características que comporiam a "essência" da capoeira. Elas encarnariam uma modalidade específica de "resistência": opor-se-iam à força bruta e dissimulariam as intenções subversivas dos que detêm este contra-poder. Para alguns defensores deste ponto de vista, os donos do contrapoder seriam os negros resistindo ao mundo dos brancos (Sodré 1983). Para outros, seriam as camadas populares lutando contra a dominação capitalista e burguesa (Salvadori 1990). Tais discursos recuperam a figura do malandro que, desde os anos 1930, encarna o anti-herói popular que recusa o mundo do trabalho e glorifica a vadiação. Ou ainda, ele é aquele que não se encontra nem na ordem, e nem fora dela, mas nos seus interstícios, utilizando-se do ambíguo como instrumento de sobrevivência (Da Matta 1990). A luta afro-brasileira é pensada aqui a partir de uma extrema alteridade em relação à sociedade dominante. A percepção dicotômica da sociedade permanece, ainda que reelaborada em função do novo contexto social e político.

Progressivamente, outras polaridades que atravessam inúmeros setores da sociedade brasileira também penetram o mundo da capoeira. Oposições como corpo/espírito e racionalidade/intuição passam a ser pensadas a partir da luta afro-brasileira. Trata-se de novas representações da pessoa, veiculadas pelos movimentos de contracultura que começam a ganhar bastante espaço na nossa sociedade. Neste contexto, a cultura ocidental moderna e o modo de produção capitalista industrial, massificado e racionalizado, passam a ser vistos como agentes que influenciam negativamente os sujeitos. Seus corpos e suas mentes teriam sido escravizados pelo sistema de dominação e, portanto, deveriam reconquistar a liberdade. A capoeira encarnaria esta possibilidade de libertação, na medida em que privilegiaria a intuição, a emoção, a malandragem e a dissimulação (Nestor Capoeira 1992 e 1995). Percebemos, assim, como a retórica da "luta do fraco contra o forte" vai ganhando novos contornos, sempre com o intuito de denunciar uma situação de opressão. Nestes casos, o alcance das representações transcende o do grupo étnico e pode aplicar-se a qualquer um que considere o modo de vida ocidental opressor e que esteja desejoso de reverter essa situação.

Apesar de sua ênfase num discurso étnico e racializado, Muniz Sodré também pode ilustrar este último tipo de representação. Em seu livro $A$ Verdade Seduzida, de 1983, a cultura ocidental moderna é pensada a partir 
da dissociação entre corpo e espírito, onde o privilégio é dado ao segundo, visto como o espaço da seriedade, da racionalização e do método, bem como da universalização e da rigidez das regras. A capoeira, ao contrário, encarna a "sabedoria africana": a "malandragem" que a caracteriza atesta sua plasticidade e sua "moral de ocasião". Encontra-se, assim, no extremo oposto da razão, regida por um processo desprovido de intelectualização, que consiste na sua "diferença cultural".

Alguns autores e praticantes enfatizam a harmonia e a coesão que perpassam o universo social dos capoeiristas, e a solidariedade passa a ser vista como um valor moral para estes (Salvadori 1990). A roda de capoeira performatizaria tanto a luta que teria ocorrido no passado, entre escravos e senhores, quanto a que ocorrerá um dia, entre os capoeiristas oprimidos e a sociedade dominante opressora (d'Aquino 1983, Lewis 1992). Apesar de reconhecerem as lutas e rivalidades internas ao mundo da capoeira, a ênfase recai nos conflitos externos, sobretudo no caso de Lewis.

Nas diferentes representações mencionadas acima, podemos perceber a valorização de uma capoeira lúdica, considerada mais africana, em detrimento de uma outra que seria mais agressiva e ocidentalizada. O conflito é quase sempre pensado como algo externo ao mundo da capoeira, e não como uma de suas características internas. Este imaginário toma conta dos capoeiristas da atualidade, para os quais violência e agressividade no jogo são sinônimos de descaracterização e se transformam em verdadeiras categorias de acusação. No entanto, esta mesma análise nos deixa entrever a enorme circulação de idéias entre a cultura popular e o universo erudito, o que nos conduz à conclusão de que a primeira não permanece intacta ou imune às influências do segundo. Mas não é meu objetivo avaliar o quão pura ou impura se encontra a capoeira dos dias de hoje, pois estaria dando continuidade à perspectiva que pretendo aqui problematizar. Limito-me a constatar esta relação bastante íntima entre estes dois universos e a levantar algumas questões. Em trabalho anterior (Vassallo 2001), procurei demonstrar que é justamente através das inúmeras relações que se tecem entre os capoeiristas e certos representantes das camadas dominantes (intelectuais, artistas, representantes do poder público) que as diversas definições da luta afro-brasileira são elaboradas pelos diferentes atores sociais envolvidos com esta atividade.

\section{O LEGADO DOS FOLCLORISTAS E A CAPOEIRA CARIOCA ATUAL}

Uma cuidadosa etnografia de algumas escolas do Rio de Janeiro, realizada a partir do final dos anos 1990, parece revelar que as imagens da capoeira que acabamos de analisar correspondem mais a um plano idealizado do que às práticas cotidianas destes ambientes.

De um modo geral, o mundo da capoeira é composto de diferentes escolas (que os capoeiristas preferem chamar de academias), cada qual liderada por um professor ou mestre e composta de diversos alunos. Tais escolas são referências básicas para seus integrantes, que pautam a sua identidade no pertencimento a elas. Cada capoeirista define-se primeiramente pela academia a que pertence e pelo mestre que a comanda. A idéia de linhagem é fundamental neste universo, ainda que o capoeirista sempre esteja livre para trocar de mestre na hora que julgar conveniente. 
Cada escola possui vários sinais diacríticos, que servem para diferenciá-la das demais e para afirmar suas especificidades. Tais sinais, ou signos, podem ser um emblema, usado no uniforme de aula; técnicas corporais específicas para a realização dos golpes e que não são compartilhadas pelas outras escolas; a inscrição numa determinada linhagem de mestres, considerados ilustres; o respeito a determinadas tradições, que os capoeiristas preferem chamar de "fundamentos"; a origem regional ou étnica (por exemplo, se o capoeirista ou o seu mestre vem de cidades como Rio de Janeiro ou Salvador, se é branco ou negro). Por trás da afirmação dessas diferenças, cada escola tenta garantir a sua superioridade sobre as demais, reivindicando para si maior poder e prestígio do que as outras. Cada qual acredita que os signos e valores veiculados na sua academia são melhores que os das outras, pois são mais eficazes, mais puros, mais tradicionais ou mais legítimos.

Mas nenhum desses componentes possui unanimidade entre os jogadores. O que é considerado tradicional em uma escola é tido como descaracterizado em outra, as técnicas corporais corretas para uns são erradas para outros, e assim por diante. Da mesma forma, tanto a procedência carioca quanto a baiana podem servir para legitimar um praticante, na medida em que ambas as regiões possuem vestígios antigos de existência da capoeira. As disputas se expressam ainda de outras maneiras, como pelo número de alunos, pelo fato de se ter ou não filiais no exterior, pelo grau de violência tolerado nas rodas ou pelo seu reverso, a mandinga do jogador, que dispensaria o uso da força. Portanto, o mundo da capoeira não é harmonioso ou coeso e a noção de conflito torna-se fundamental para a sua compreensão. Ainda que ele seja atravessado por redes de solidariedade e ajuda mútua, também conta com inúmeras divergências e disputas entre as diversas academias e seus respectivos professores e alunos. Cada capoeirista, através da sua academia, está o tempo todo tentando afirmar que o seu jeito de praticar a capoeira é superior ao dos colegas vindos das outras instituições.

O combate que se trava entre os membros das diferentes escolas é, acima de tudo, um combate semântico. Cada qual luta pelo privilégio de poder definir a capoeira ao seu modo - impondo os seus próprios critérios para distinguir o certo do errado, o puro do espúrio, o tradicional do degenerado, o belo do feio - e de ditar a sua definição às demais. Ou seja, disputa-se a maneira mais correta de praticá-la. Portanto, o mundo da capoeira parece ser altamente polissêmico, possuindo diversas maneiras de ser praticado e interpretado. Daí a importância da fidelidade a uma única escola, pois não há consenso entre as escolas a respeito de como se deve jogar capoeira.

Mesmo dentro de uma única academia, o conflito também pode ser observado. Nesta, cada praticante compete com os colegas em relação à proximidade do mestre, ao domínio das técnicas corporais e do manuseio dos instrumentos musicais, à quantidade de vezes de vezes que entra na roda para jogar... O jogo de cada dupla é minuciosamente analisado pelos pares em função de quem está "ganhando" ou "perdendo", ainda que não haja nenhum critério objetivo para a avaliação destas performances. Enquanto participa da roda, cada indivíduo tenta se sobressair em relação aos colegas.

Mas se este ambiente altamente hierarquizado e competitivo pode ser observado no cotidiano das escolas de capoeira da atualidade, como poderíamos explicar que as representações desta luta, realizadas tanto por capoeiristas quanto por intelectuais, enfatizam de modo tão acentuado o contrário, ou seja, a idéia de harmonia e coesão? 
Em primeiro lugar, podemos notar a importância do legado dos folcloristas, que se reelabora através das décadas, conquistando o senso comum. Mas, se estas representações não só permanecem como parecem adquirir mais força, é porque fazem sentido para os capoeiristas. Cabe ao pesquisador justamente a tarefa de analisar o significado destas manipulações simbólicas.

Vejo estas narrativas como maneiras de criar uma imagem positiva da capoeira e dos capoeiristas da atualidade. Esta atividade, que foi alvo de tantos preconceitos até muito pouco tempo atrás, passa a ser vista sob um prisma guerreiro, heróico e enaltecedor. Nesta perspectiva, o capoeirista se vê como dono do seu próprio destino, conquistado através da luta. A sociedade mais abrangente é pensada a partir da sua negatividade, ao passo que a capoeira encarna uma imagem épica e romântica, uma solução contra a opressão do presente. Contribuiria, então, positivamente, para o povo negro e para os que se consideram oprimidos, bem como para a sociedade em geral, através do seu aspecto de insubordinação, inclusive ao sistema capitalista. Deste modo, os capoeiristas constroem uma identidade positiva, que serve tanto individual quanto coletivamente, mas que deve ser manuseada com extremo cuidado pelos pesquisadores da atualidade, para que as categorias nativas sejam vistas como objetos de reflexão, e não como verdades inquestionáveis prontas para serem reproduzidas.

Simone Pondé Vassallo é doutora em Antropologia Social e Etnologia pela École des Hautes Études en Sciences Sociales (Paris) e professora visitante do Programa de Pós-Graduação em Ciências 


\section{NOTAS}

1 Utilizo o termo "folcloristas" de maneira bastante ampla, sabendo que a produção dos autores englobados por esse rótulo é mais abrangente. Incluo até autores que, sob diversos aspectos, condenaram a perspectiva folclorista em prol de uma abordagem sociológica, como Roger Bastide.

2 Para uma problematização da polarização da capoeira em Angola e Regional e da construção da Capoeira Angola como paradigma de pureza, ver Vassallo 2003

\section{REFERÊNCIAS BIBLIOGRÁFICAS}

ALMEIDA, Renato. 1961 [1942]. “O Brinquedo da Capoeira". In Tablado Folclórico. São Paulo : Ricordi Brasileira.

AMARAL, Braz Hermenegildo do. [19_?]. Os Grandes Mercados de Escravos Africanos. Rio de Janeiro: Livraria João Leite.

BASTIDE, Roger. 1971 [1960]. As Religiões Africanas no Brasil. São Paulo: Livraria Pioneira/USP. 1996 [1968]. Les Amériques Noires. 3ed. Paris: L'Harmattan.

BOYER, Véronique. 1993. “Les Traditions Risquent-elles d'être Contaminées? Paradigmes scientifiques et orthodoxie religieuse dans les cultes de possession au Brésil". Journal de la Société des Américanistes 79: 67-90.

CAPOEIRA, Nestor. 1992. Os Fundamentos da Malícia. Rio de Janeiro: Record.

. 1995. Ritual Roda: mandinga x tele-real. Dissertação de Mestrado da Escola de Comunicação. Rio de Janeiro: Universidade Federal do Rio de Janeiro.

CAPONE, Stefania. 1999. La Quête de l'Afrique dans le Candomblé. Pouvoir et tradition au Brésil. Paris: Karthala. 2000. "Entre Yoruba et Bantou: I'influence des stéréotypes raciaux dans les études afro-américaines". Cahiers d'Études Africaines 157 (XL-1): 55-77.

CARNEIRO, Édison. 1937. Negros Bantus. Notas de etnografia religiosa e de folk-lore. Rio de Janeiro: Civilização Brasileira. 1950. Dinâmica do Folklore. Rio de Janeiro: O Autor. . 1975. "Capoeira". Cadernos de Folclore 1. Rio de Janeiro: Funarte/MEC.

CASCUDO, Luís da Câmara. 1967. Folclore do Brasil. Rio de Janeiro: Editora Fundo de Cultura.

. 1993 [1954]. “Capoeira”. In Dicionário do Folclore Brasileiro. 7a ed.. Belo Horizonte; Rio de Janeiro: Itatiaia.

DaMATTA, Roberto. 1993 [1987]. "A Fábula das Três Raças, ou o Problema do Racismo à Brasileira". In Relativizando: uma introdução à antropologia social. $4^{\mathrm{a}}$ ed. Rio de Janeiro: Rocco. Guanabara.

. 1990. Carnavais, Malandros e Heróis. Para uma sociologia do dilema brasileiro. 5.ed.. Rio de Janeiro:

DANTAS, Beatriz Góis. 1988. Vovó Nagô e Papai Branco: usos e abusos da África no Brasil. Rio de Janeiro: Graal. 
D'AQUINO, Iria. 1983. Capoeira: Strategies for Status, Power and Identity. Ph.D. Dissertation. Illinois: University of Illinois.

FREYRE, Gilberto. 1988 [1944]. Prefácio a Luís Viana Filho. In L. Viana Filho. O Negro na Bahia. 3a ed.. Rio de Janeiro: Nova Fronteira.

HOLLOWAY, Thomas. 1989. “O Saudável Terror: repressão policial aos capoeiras e resistência dos escravos no Rio de Janeiro do século XIX". Estudos Afro-Asiáticos 16: 129-140.

LEWIS, John Lowell. 1992. Ring of Liberation. Deceptive discourse in Brazilian Capoeira. Chicago: University of Chicago Press.

MARTÍNEZ-ECHAZÁBAL, Lourdes. 1998. “O Culturalismo dos Anos 30 no Brasil e na América Latina: deslocamento retórico ou mudança conceitual?". In M.C. Maio \& R.V. Santos (orgs.) Raça, Ciência e Sociedade. Rio de Janeiro: Fiocruz.

PIRES, Antônio Liberac Cardoso Simões. 1996. A Capoeira no Jogo das Cores: criminalidade, cultura e racismo na cidade do Rio de Janeiro (1890-1937). Dissertação de Mestrado em História. Campinas: Universidade de Campinas.

REIS, Letícia Vídor de Souza. 1993. Negros e Brancos no Jogo da Capoeira: a reinvenção da tradição. Dissertação de Mestrado em Antropologia Social. São Paulo: Universidade de São Paulo.

SALVADORI, Maria Ângela Borges. 1990. Capoeiras e Malandros: pedaços de uma sonora tradição popular (1890-1950). Dissertação de Mestrado em História. Campinas: Universidade de Campinas.

SCHWARCZ, Lilia Katri Moritz. 1995. “Complexo de Zé Carioca. Notas para uma identidade mestiça e malandra”. Revista Brasileira de Ciências Sociais 29: 49-63.

SOARES, Carlos Eugênio Líbano. 1994. A Negregada Instituição. Os capoeiras no Rio de Janeiro. Rio de Janeiro: Coleção Biblioteca Carioca. de Campinas.

2001. A Capoeira Escrava e Outras Tradições Rebeldes no Rio de Janeiro (1808-1850). Campinas: Universidade

SODRÉ, Muniz. 1983. “Capoeira, um Jogo de Corpo”. In A Verdade Seduzida. Por um conceito de cultura no Brasil. Rio de Janeiro: Codecri.

TAVARES, Júlio César. 1984. Dança da Guerra: arquivo-arma. Dissertação de Mestrado em Sociologia. Brasília: Universidade de Brasília.

VASSALLO, Simone Pondé. 2001. Ethnicité, Tradition et Pouvoir: le jeu de la capoeira à Rio de Janeiro et à Paris. Tese de Doutorado em Antropologia Social e Etnologia. Paris: École des Hautes Études en Sciences Sociales.

. 2003. “Capoeiras e Intelectuais: a construção coletiva da capoeira 'autêntica'”. Estudos Históricos 32: 106-124.

2004. "Atribuição ou Aquisição? As relações entre etnicidade, tradição e poder para capoeiristas brasileiros e franceses em Paris". Revista Interseções, ano 6, no 2: 333-344.

VIANA FILHO, Luís. 1988 [1944]. O Negro na Bahia. 3a ed.. Rio de Janeiro: Nova Fronteira.

VIEIRA, Luiz Renato. 1990. Da Vadiação à Capoeira Regional: uma interpretação da modernização cultural no Brasil. Dissertação de Mestrado em Sociologia. Brasília: Universidade de Brasília.

VILHENA, Luís Rodolfo. 1997. Projeto e Missão. O movimento folclórico brasileiro, 1947-1964. Rio de Janeiro: Funarte/ Fundação Getúlio Vargas. 


\section{Resistência ou Conflito? O legado folclorista nas atuais representações do jogo da capoeira}

\section{RESUMO}

Este artigo procura compreender alguns dos motivos que levam a uma enorme disparidade entre uma imagem idealizada do jogo da capoeira, visto principalmente como um espaço da harmonia e da coesão social, e certas práticas cotidianas extremamente hierarquizadas e competitivas, veiculadas pelos próprios capoeiristas. Sugiro que este hiato entre representação e ação resulte de uma atualização da perspectiva de folcloristas brasileiros de meados do século $X X$, e que deve, portanto, ser alvo de reflexão. A análise se dá a partir da leitura de algumas obras publicadas por pesquisadores e por capoeiristas, desde a década de 1930, bem como de uma etnografia realizada em algumas escolas de capoeira do Rio de Janeiro, nos dias de hoje.

PALAVRAS-CHAVE: capoeira; conflito; cordialidade; culturalismo; folclore

\section{Resistence or Conflict? The folklorist legacy in contemporary representations of the capoeira game}

\section{ABSTRACT}

This article examines some of the motives underlying the enormous disparity between the idealized public image of the capoeira game, seen primarily as a space of harmony and social cohesion, and some extremely hierarchized and competitive everyday practices in which the capoeira performers are themselves engaged. I suggest that this gap between representation and action results from a latter-day version of a view held by mid-20 $20^{\text {th }}$ century Brazilian folklorists, and that therefore should be carefully re-evaluated. My analysis is based on various works published by researchers and capoeira performers since the 1930s, as well as on an ethnography conducted in a number of capoeira schools of Rio de Janeiro.

KEY WORDS: capoeira game; conflict; cordiality; culturalism; folklore.

Recebido em 12/07/2005

Aprovado em 15/05/2006 